\title{
Prognostic Value of Circulating Microvesicle Subpopulations in Ischemic Stroke and TIA
}

\author{
Annika Lundström ${ }^{1}$ (D) Fariborz Mobarrez ${ }^{2}$ • Elisabeth Rooth ${ }^{1} \cdot$ Charlotte Thålin ${ }^{1} \cdot$ Magnus von Arbin ${ }^{1}$. \\ Peter Henriksson $^{3} \cdot$ Bruna Gigante $^{3,4} \cdot$ Ann-Charlotte Laska $^{1} \cdot$ Håkan Wallén $^{3}$
}

Received: 3 October 2019 / Revised: 3 December 2019 / Accepted: 23 December 2019 / Published online: 25 January 2020

(C) The Author(s) 2020

\begin{abstract}
Platelet microvesicles (PMV) have previously been found elevated in acute ischemic stroke (IS) and could be biomarkers for risk of recurrence. PMV surface antigens such as P-selectin and phosphatidylserine (PS) reflect platelet activation and procoagulance. Tissue factor-positive microvesicles $\left(\mathrm{TF}^{+} \mathrm{MV}\right)$ are considered procoagulant, in particular if co-expressing PS. We enumerated MV subpopulations with these surface antigens in a cohort of 211 patients with primarily non-cardioembolic IS or transient ischemic attack (TIA) and investigated their association with long-term outcome. MV concentrations were determined by flow cytometry in the acute and convalescent phase. Primary outcome was a composite of fatal and non-fatal recurrent IS or myocardial infarction. Secondary outcomes were recurrent IS and all-cause mortality. Outcome events were obtained from Swedish registers during a follow-up of 1100 patient years. Concentrations of PS-positive and PS-negative MV populations were elevated in patients compared with healthy controls in both the acute and convalescent phase. $\mathrm{PS}^{+} \mathrm{TF}^{+} \mathrm{PMV}$ displayed pronounced elevations, median fold change 77 in the acute phase $(p<0.0001)$ but were not associated with outcome, neither were $\mathrm{PS}^{+} \mathrm{P}_{-}$ selectin ${ }^{+} \mathrm{PMV}$. The only subpopulation positively associated with primary outcome was $\mathrm{PS}^{-} \mathrm{TF}^{+} \mathrm{PMV}$, with adjusted hazard ratio of $1.86(1.04-3.31, p=0.036)$ by Cox regression. Unexpectedly, several MV subpopulations tended to be associated with reduced risk of poor long-term outcome. Our results suggest that $\mathrm{PS}^{+} \mathrm{TF}^{+} \mathrm{PMV}$ may be a promising marker for cerebral ischemia, and that the in vivo generation of PS ${ }^{-}$MV after IS/TIA warrants further study. Future MV studies should ideally enumerate PS $^{+}$ and $\mathrm{PS}^{-} \mathrm{MV}$ subpopulations separately.
\end{abstract}

Keywords Ischemic stroke $\cdot$ TIA $\cdot$ Microvesicles $\cdot$ Platelet $\cdot$ Phosphatidylserine

\section{Introduction}

Electronic supplementary material The online version of this article (https://doi.org/10.1007/s12975-019-00777-w) contains supplementary material, which is available to authorized users.

Annika Lundström

annika.lundstrom@ki.se

1 Division of Internal Medicine, Department of Clinical Sciences, Karolinska Institutet, Danderyd University Hospital, SE-182 88 Stockholm, Sweden

2 Department of Medical Sciences, Division of Cancer Pharmacology and Computational Medicine, Uppsala University, Uppsala, Sweden

3 Division of Cardiovascular Medicine, Department of Clinical Sciences, Karolinska Institutet, Danderyd University Hospital, Stockholm, Sweden

4 Division of Cardiovascular Medicine, Department Medicine, Karolinska Institutet, Stockholm, Sweden
Ischemic stroke (IS) is one of the most common cardiovascular diseases and a major cause of morbidity and mortality globally [1]. Platelet function has a central role in IS; platelet activation is enhanced and remains elevated several months after an acute event [2-4]. Platelet activation causes release of platelet-derived microvesicles (PMV) which are 0.1-1.0 $\mu \mathrm{m}$ vesicles that bud off from the plasma membrane and can be detected in peripheral blood as markers of platelet activation. The procoagulant function of PMV was noted already at their discovery [5] and is attributed to exposure of phosphatidylserine (PS) and binding of coagulation factors [6-9]. More recently, the role of PMV in atherosclerosis/ vascular inflammation and also in tissue regeneration has been recognized $[10,11]$. Notably, PMV are heterogenous, with morphology, surface antigens, and content depending on platelet agonist(s) and pathological circumstances [12-14]. 
Tissue factor-positive microvesicles $\left(\mathrm{TF}^{+} \mathrm{MV}\right)$ are of interest for thrombotic diseases such as IS. TF, a main initiator of coagulation, was originally thought to reside exclusively on cells of the "hemostatic envelope" [15]. Ground-breaking work around the turn of the century demonstrated the existence of circulating MV-expressing TF, which were found to incorporate into thrombi and supported fibrin formation [16, 17]. Coexpression of $\mathrm{PS}$ on $\mathrm{TF}^{+} \mathrm{MV}$ is thought to increase procoagulance further $[18,19]$. It has been postulated that primarily monocytes release $\mathrm{TF}^{+} \mathrm{MV}$ into the circulation $[18$, 20]. We and others have previously detected circulating $\mathrm{TF}^{+} \mathrm{PMV}[21,22]$. This finding is controversial as platelets are generally not thought to express TF [20]. However, two in vitro studies show that leukocyte TF can be transferred to platelets $[23,24]$. Circulating $\mathrm{TF}^{+} \mathrm{MV}$ may thus reflect monocyte activation, and circulating $\mathrm{TF}^{+} \mathrm{PMV}$ may reflect platelet and leukocyte activation, or their interactions. Cell-cell interactions and the crosstalk between the hemostatic and innate immune systems at the vessel wall are increasingly recognized as critical for both thrombosis and inflammation; the terms "immunothrombosis" and "thromboinflammation" have been proposed $[25,26]$. Thromboinflammatory processes, including generation of MV, are likely activated in ischemic cerebral vasculature and ischemia-reperfusion injury after stroke, especially as brain injury in stroke causes peripheral immune responses characterized by both activation and suppression [27]. $\mathrm{PMV}$ and $\mathrm{TF}^{+} \mathrm{MV}$ are thus interesting candidate biomarkers for IS. Previously, levels of PMV, $\mathrm{TF}^{+} \mathrm{MV}$, and MV with TF activity were found to be elevated in IS [28-31], but as yet there is a lack of prospective studies, establishing prognostic value.

Importantly, recent findings suggest that MV biology is more complex than previously recognized. Flaumenhaft et al. showed that megakaryocytes constitutively release MV which may be counted as PMV when detected in peripheral circulation; these MV express PS but not P-selectin [32]. It has therefore been proposed that P-selectin-positive PMV are more suitable markers of platelet activation than PMV overall $[21,33]$. Also, while PS expression is considered intimately associated with MV release [34, 35], Arraud et al. showed by cryo-transmission electron microscopy that about half of PMV in healthy persons do not express PS as detected by annexin V [36]. Notably, little is known about such PS $^{-}$MV and their role in health or disease.

The aim of this study was to perform subtyping of PMV and $\mathrm{TF}^{+} \mathrm{MV}$ in patients with IS/TIA and to determine associations between MV populations and long-term outcome. Based on previous work on acute coronary syndrome (ACS), we expected the majority of MV to be PMV and $\mathrm{TF}^{+} \mathrm{MV}$ to be rare [21]. We hypothesized that the strongest association to poor outcome would be found for (a) $\mathrm{PS}^{+} \mathrm{P}$ selectin ${ }^{+} \mathrm{PMV}$, reflecting "true" platelet activation without megakaryocyte contribution, and (b) $\mathrm{PS}^{+} \mathrm{TF}^{+} \mathrm{MV}$ with or without co-expression of platelet marker due to high procoagulant potential. With respect to PS-negative populations and their association with long-term risk, the study was considered hypothesis generating as this has not been previously studied in detail.

\section{Materials and Methods}

\section{Study Population and Evaluation of Outcome}

The study PROPPSTOPP recruited 249 patients with minor IS or TIA from two stroke units in Stockholm, Sweden (Danderyd Hospital and Södersjukhuset) between 2007 and 2009. The original study had two objectives: (1) to screen for occult atrial fibrillation (AF) (completed [37]) and (2) to measure MV and variables of hemostasis [38]. Samples were collected in the acute/subacute phase of the index event, as well as in the convalescent phase 1 month later. Inclusion criteria were IS or TIA within 14 days of inclusion and age above 65 years (initially the age limit was $>45$ years, but it was raised to obtain a more representative stroke cohort). Exclusion criteria were AF (known or present on admission ECG) and inability to perform screening with a handheld ECG device after discharge. In total, 38 patients were excluded before follow-up, due to incorrect diagnosis, patient request, or complete lack of blood samples, resulting in a cohort of 211 patients. MV analyses were performed for 199 patients in the acute phase and for 189 patients in the convalescent phase. Patients received secondary prevention for IS/TIA and treatment of risk factors at the discretion of the responsible physician.

Primary outcome was a composite of fatal or non-fatal recurrent IS and acute myocardial infarction (AMI). Secondary outcomes were recurrent IS and all-cause mortality respectively. Events and dates of events were retrieved from the Swedish Register of in-patient care and the Register for cause of death and were verified against hospital records. Patients were followed up until 31 Dec 2014 and censored after a first event with respect to the outcome evaluated.

For comparison, 53 age- and sex-matched healthy controls were recruited. They were not treated for hypertension or hyperlipidemia and received no antithrombotic, oral corticosteroid, or SSRI medication. Mild hypertension $(<150 \mathrm{mmHg}$ systolic blood pressure without treatment), mild to moderate hyperlipidemia (total cholesterol $<8 \mathrm{mmol}^{-1}$ ), limited chronic kidney disease (plasma creatinine $<140 \mu \mathrm{mol} \mathrm{l}^{-1}$ ), wellsubstituted thyroid dysfunction, and successfully treated cancer more than 2 years before inclusion was allowed.

\section{Clinical and Routine Laboratory Evaluation}

Medical history, clinical/anthropometric measures, and routine blood samples were taken at inclusion. Stroke severity 
was estimated by National Institutes of Health Stroke Scale (NIHSS). Routine blood/plasma analyses were performed by the Laboratory of Clinical Chemistry, Karolinska University Hospital, Stockholm, Sweden. Estimated glomerular filtration rate (eGFR) was calculated from plasma creatinine by the Modification of Diet in Renal Disease (MDRD) formula.

\section{Blood Sampling and Plasma Preparation}

Blood was drawn from an antecubital vein, with no or minimal stasis and after rest for at least $10 \mathrm{~min}$ in recumbent position. For healthy controls, patients in the convalescent phase, and most patients in the acute phase (56\%), blood sampling was performed in the morning after an overnight fast. For the remainder of patients (44\%), acute phase blood sampling was performed in a non-fasting state due to short time between inclusion and patient discharge, taking care to avoid blood sampling after a meal. Platelet-poor plasma (PPP) was prepared immediately from citrated whole blood by centrifugation at $2000 \times \mathrm{g}$ for $20 \mathrm{~min}$ in room temperature (RT) and was aliquoted and frozen at $-80^{\circ} \mathrm{C}$ until analysis. Blood samples were taken median 3 days (interquartile range (IQR), 2 5 days) after symptoms in the acute phase and 36 days (IQR, 34-39 days) after symptoms in the convalescent phase.

\section{Microvesicle Analyses}

The process for MV isolation and labeling has been described previously $[21,39]$. In short, frozen PPP was thawed in waterbath $\left(37^{\circ} \mathrm{C}\right)$ for approximately $5 \mathrm{~min}$ and centrifuged at $2000 \times \mathrm{g}$ for $20 \mathrm{~min}$ in RT. The supernatant (SN) was recentrifuged at $13,000 \times \mathrm{g}$ in RT for $2 \mathrm{~min}$. Twenty microliters of the final SN was incubated for $20 \mathrm{~min}$ in the dark with $5 \mu \mathrm{l}$ each of the appropriate fluorescent surface markers: phalloidin-Alexa 660 for actin (Invitrogen, Paisley, UK), lactadherin-FITC for PS (Haematologic Technologies, VT, USA), mouse antihuman CD41-PC7 for GPIIb of the platelet GPIIbIIIa receptor (Beckman Coulter Inc., CA, USA), mouse antihuman CD62P-APC for P-selectin (BD, NJ, USA), and mouse antihuman CD142-PE for TF (clone HTF-1, BD, NJ, USA) or corresponding non-specific isotype mouse IgGantibodies as negative controls.

Samples were analyzed in 2010 by a Beckman Coulter Gallios flow cytometer with established MV sensitivity and threshold set on forward scatter. The MV gate was determined by analyzing beads prior to samples (Megamix beads, 0.5, 0.9, and $3.0 \mu \mathrm{m}$; Biocytex, Marseille, France). MV events were defined as less than $0.9 \mu \mathrm{m}$ in size as shown in Supplemental Fig. 1a. MV were labeled with lactadherin in order to optimize sensitivity for $\mathrm{PS}^{+} \mathrm{MV}$ [40]. The concentration of added lactadherin-FITC was $8 \mu \mathrm{g} \mathrm{ml}^{-1}$. The gating strategy to separate $\mathrm{PS}^{+}$and $\mathrm{PS}^{-} \mathrm{MV}$ populations is shown in Supplemental Fig. 1b. Gating for enumeration of PMV subpopulations are shown in Supplemental Fig. 1c, d for PSpositive PMV; the same gating was used for PS-negative PMV. Gate settings were fixed for all analyses. Events were counted for $30 \mathrm{~s}$ at fixed flow rate (medium setting) and MV concentration calculated by dividing by flow volume as established by counting of beads of known concentration. MV enumeration by this method had inter- and intra-assay coefficients of variation less than $9 \%$ in a previous study by our group using a similar protocol [41]. Phalloidin-positive MV were used for sample quality control. Phalloidin binds actin of cell fragments which may be counted as MV. Good sample quality was defined as less than $10 \%$ phalloidinpositive events of total MV count. MV enumeration is presented as total number of MV with expression of the specified antigen(s), e.g., $\mathrm{PS}^{+} \mathrm{PMV}$ include all MV with surface markers $\mathrm{PS}$ and GPIIb including $\mathrm{PS}^{+} \mathrm{P}-$-selectin ${ }^{+} \mathrm{PMV}$ and $\mathrm{PS}^{+} \mathrm{TF}^{+} \mathrm{PMV}$. An illustration of analyzed MV populations and their presumed cell of origin is shown in Fig. $1 . \mathrm{TF}^{+} \mathrm{MV}$ lacking the platelet marker GPIIb are denoted "non-platelet $\mathrm{TF}^{+} \mathrm{MV}$ " below.

\section{Statistical Methods}

Normally distributed, continuous variables are presented as mean with standard deviations; non-normally distributed, continuous variables are presented as median with IQR. Differences between independent groups were analyzed by two-sided Student $t$ test or Mann-Whitney $U$ test as appropriate. Dependent variables were analyzed by paired Student $t$ test or Wilcoxon test as appropriate. Correlations between independent variables were calculated by Spearman's rank correlation coefficient, since several variables had nonnormal distribution. Categorical variables are presented as numbers with proportions and were compared by $\chi^{2}$ test or Fisher's exact test as appropriate.

The prospective analysis of outcome was performed in steps. In a first variable screening, patients with and without outcome events were compared by descriptive statistics and two-sided Student $t$ test or Mann-Whitney $U$ test as appropriate. Variables with $p<0.2$ for difference were retained. In a second step, the cohort was divided by median split for the variable analyzed, with subsequent Kaplan-Meier analysis and $\log$ rank test for difference. Variables with $p<0.1$ for difference were included in multivariate, forward stepwise Cox regression analysis adjusted for cardiovascular risk factors in order of importance. The number of variables in the final multivariate model was limited so as to have eight to ten patients with events per variable in order not to overfit the model. The number of analyzed patients with and without events for each test is presented in respective tables and figures.

$p$ values $<0.05$ were considered statistically significant in baseline analyses and in the final multivariate model. Data 


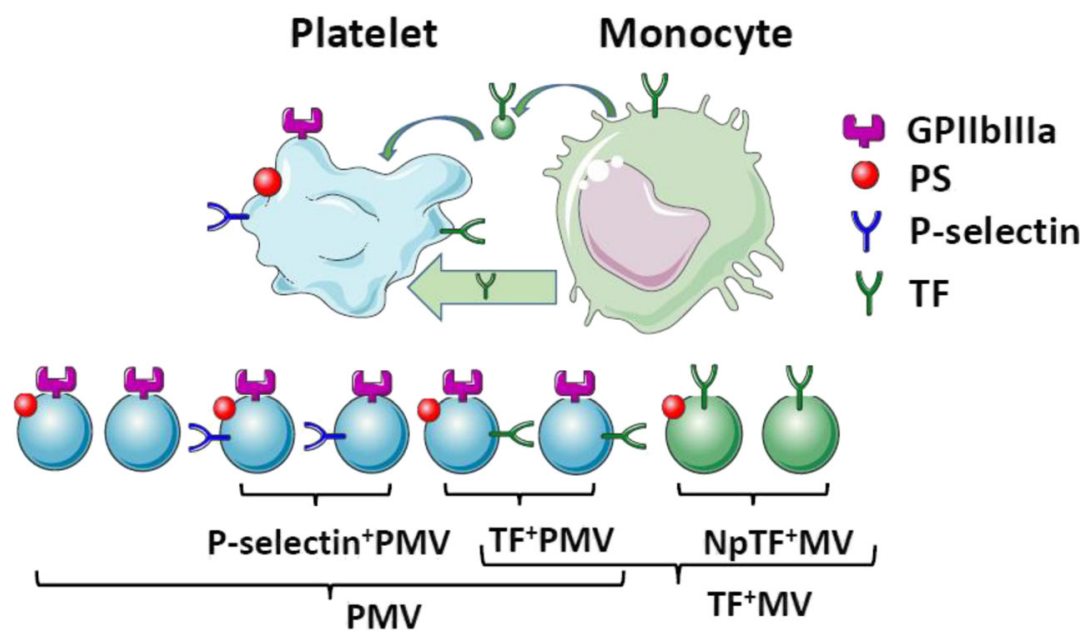

Fig. 1 Schematic view of analyzed platelet microvesicles (PMV) and tissue factor (TF)-positive microvesicles $\left(\mathrm{TF}^{+} \mathrm{MV}\right)$ with their presumed cell of origin. Platelets express surface integrin GPIIbIIIa (dark purple) abundantly. Platelet activation causes exposure of phosphatidylserine (PS, red). Activated platelets release different PMV (light blue), positive or negative for PS. P-selectin-positive (dark blue) PMV (Pselectin $\left.^{+} \mathrm{PMV}\right)$ signal platelet activation including degranulation of $\alpha$ granules. Primarily monocytes are thought to express TF (dark green). Monocyte TF may be transferred to platelets via uptake of monocyte MV

were analyzed by SPSS version 23 (IBM, IL, USA) and figures created by Prism (GraphPad Software Inc., CA, USA).

\section{Results}

\section{Cohort Characteristics and Outcome}

The clinical characteristics and laboratory data for the study cohort and healthy controls are presented in Table 1. Data from the Swedish Stroke Register are added for comparison where possible. The composite primary outcome occurred in 54 patients during a follow-up time of 1100 patient years. Forty-one patients had recurrent IS, twelve AMI (five of which were fatal), and one patient had both AMI and IS. Clinical characteristics of patients with and without primary outcome are included in Table 1 . The secondary outcome recurrent IS occurred in 43 patients (including two who had AMI prior to recurrent IS). Thirty-one patients died. Five patients had a recurrent IS between acute and convalescent blood sampling. They were excluded from the prospective analysis of convalescent MV populations.

Medication in the acute and convalescent phase as compared with the Swedish Stroke Register is shown in Supplementary Table 1 . The vast majority of patients received antiplatelet treatment $(96 \%$ in the acute phase and $95 \%$ in the convalescent phase) with aspirin being the most common treatment. A limited number of patients received anticoagulant treatment. Anticoagulation in the (light green) or cell interactions (broad light green arrow). Subsequent platelet activation may lead to release of $\mathrm{TF}^{+} \mathrm{PMV}$. Non-platelet $\mathrm{TF}^{+} \mathrm{MV}$ $\left(n p \mathrm{TF}^{+} \mathrm{MV}\right.$, green) primarily from monocytes can also be released directly into the circulation. PMV lacking activation markers P-selectin and TF form a subset of PMV and were not enumerated separately. Sizes of cells, $\mathrm{MV}$, and surface markers are non-proportional for clarity. The figure was created with images from Servier Medical Art, licensed under Creative Common Attribution 3.0 Unported License

acute phase was generally low molecular weight heparin for prevention of venous thrombosis or due to multiple TIA. In the convalescent phase, 11 patients received warfarin, see Supplementary Table 1 for details.

Patients with primary outcome events were on average almost 3 years older and had higher prevalence of diabetes and higher plasma creatinine than patients without events, see Table 1. Unexpectedly, LDL-cholesterol in the acute phase was lower for patients with than without primary outcome, while there was no difference in statin treatment. LDLcholesterol could thus not be used as a risk marker in this cohort. Based on Cox regression, cardiovascular risk factors had the following univariate associations to primary outcome (in order of importance): diabetes (HR, 2.2; $p=0.014$ ), reduced kidney function with eGFR $<60 \mathrm{ml} \mathrm{m^{-1 }} 1.73 \mathrm{~m}^{-2}$ (HR, $2.0 ; p=0.028)$, age $>70$ years (HR, $1.9 ; p=0.038$ ), and male sex (HR, $1.8 ; p=0.054)$. Hypertension $(p=0.26)$ and smoking at inclusion $(p=0.52)$ were less clear risk factors in this cohort.

\section{Baseline MV Concentrations}

MV isolation was of good quality with median $6.0 \%$ (IQR, 3$9 \%$ ) of events being positive for phalloidin $[39,42]$. The concentrations of MV populations are shown in Table 2. For both patients and controls, the majority of MV were $\mathrm{PS}^{+}$, and the majority were PMV for both $\mathrm{PS}^{+} / \mathrm{PS}^{-} \mathrm{MV}$. Levels of total MV concentrations and $\mathrm{PS}^{+} / \mathrm{PS}^{-} \mathrm{MV}$ were moderately elevated in patients compared with healthy controls. 
Table 1 Clinical and laboratory characteristics for the entire patient cohort, patients without and with primary outcome event (prim outcome), healthy controls and all Swedish stroke patients (data from the Swedish Stroke Register)

\begin{tabular}{|c|c|c|c|c|c|}
\hline & $\begin{array}{l}\text { Patient cohort } \\
N=211\end{array}$ & $\begin{array}{l}\text { Patient without prim outcome } \\
N=157\end{array}$ & $\begin{array}{l}\text { Patient with prim outcome } \\
N=54\end{array}$ & $\begin{array}{l}\text { Healthy controls } \\
N=53\end{array}$ & $\begin{array}{l}\text { Stroke register } 2011 \\
N \approx 25,000\end{array}$ \\
\hline Age at inclusion (years) & $72.3 \pm 8.2$ & $71.5 \pm 8.2$ & $74.4 \pm 7.9^{*}$ & $70.4 \pm 7.8$ & 75.9 \\
\hline Female $(n(\%))$ & $89(42 \%)$ & $72(46 \%)$ & $17(31 \%)$ & $(42 \%)$ & $48 \%$ \\
\hline \multicolumn{6}{|l|}{ Medical history at inclusion } \\
\hline Hypertension $(n(\%))$ & $139(66 \%)$ & $101(64 \%)$ & $39(72 \%)$ & & $61 \%$ \\
\hline Diabetes $(n(\%))$ & $32(15 \%)$ & $19(12 \%)$ & $13(24 \%)^{*}$ & & $24 \%$ \\
\hline Active smoker $(n(\%))$ & $38(18 \%)$ & $29(19 \%)$ & $8(14 \%)$ & & $13 \%$ \\
\hline Previous IS/TIA (n (\%)) & $53(25 \%)$ & $35(22 \%)$ & $18(33 \%)$ & & $37 \%$ \\
\hline $\operatorname{IHD}(n(\%))$ & $38(18 \%)$ & $26(17 \%)$ & $13(24 \%)$ & & \\
\hline TIA as index event $(n(\%))$ & $72(34 \%)$ & $54(34 \%)$ & $17(31 \%)$ & & \\
\hline NIHSS & $0(0-1)$ & 0 & 0 & & \\
\hline BMI at inclusion $\left(\mathrm{kg} \mathrm{m}^{-2}\right)$ & $25.8 \pm 3.8$ & $25.9 \pm 3.8$ & $25.5 \pm 3.9$ & & \\
\hline Hemoglobin $\left(\mathrm{g}^{-1}\right)$ & $141 \pm 13$ & $141 \pm 13$ & $141 \pm 15$ & $137 \pm 10$ & \\
\hline Leukocyte count $\left(\times 10^{9} 1^{-1}\right)$ & $6.9(5.9-8.9)$ & 6.9 & 6.9 & $5.0(4.3-5.5)$ & \\
\hline Platelet count $\left(\times 10^{9} 1^{-1}\right)$ & $214(181-262)$ & 213 & 214 & $216(184-235)$ & \\
\hline Hs-CRP (mg l-1) & $2.5(0.9-6.4)$ & 2.55 & 2.40 & $0.72(0.27-1.14)$ & \\
\hline P-glucose (mM) & $6.4(5.6-7.7)$ & 6.3 & 6.5 & $5.4(5.0-5.6)$ & \\
\hline Creatinine $(\mu \mathrm{M})$ & $80(70-93)$ & 79 & $86^{*}$ & $70(63-84)$ & \\
\hline eGFR (ml min $\left.\min ^{-1} 1.73 \mathrm{~m}^{-2}\right)$ & $79 \pm 20$ & $80 \pm 19$ & $76 \pm 22$ & $89 \pm 14$ & \\
\hline LDL-cholesterol (mM) & $3.2 \pm 0.9$ & $3.3 \pm 1.0$ & $3.0 \pm 0.8^{*}$ & $3.6 \pm 0.8$ & \\
\hline
\end{tabular}

$I S$, ischemic stroke; TIA, transient ischemic attack; IHD, ischemic heart disease; NIHSS, National Institute of Health Stroke Scale; BMI, body mass index; $e G F R$, estimated glomerular filtration rate

$*$ signifies statistical probability $p<0.0001$

\section{Concentrations of PMV and P-Selectin-Positive PMV}

Concentrations of PMV and P-selectin-positive PMV with respectively without PS are shown in Fig. 2, where Fig. 2a shows $\mathrm{PS}^{+}$populations. $\mathrm{PS}^{+} \mathrm{PMV}$ were moderately elevated in the acute phase and decreased but remained significantly elevated compared with healthy controls in the convalescent phase. $\mathrm{PS}^{+} \mathrm{P}$-selectin ${ }^{+} \mathrm{PMV}$ displayed pronounced elevations relative to healthy controls (fold change 7 in the acute phase), which decreased in convalescent phase. Figure $2 b$ shows the corresponding PS $^{-}$populations. These display a different time profile, with increasing concentrations between the acute and convalescent phase.

\section{TF $^{+}$PMV Concentrations}

Concentrations of $\mathrm{TF}^{+} \mathrm{PMV}$ populations are shown in Fig. 3 . Patients displayed unexpectedly high concentrations of both $\mathrm{PS}^{+} \mathrm{TF}^{+} \mathrm{PMV}$ and $\mathrm{PS} \mathrm{TF}^{+} \mathrm{PMV}$, median fold change 77 and 15 times $(p<0.0001)$ respectively in the acute phase compared with healthy controls. Levels decreased but remained substantially elevated in the convalescent phase. The proportion of $\mathrm{PS}^{+} \mathrm{PMV}$ expressing $\mathrm{TF}$ was median $12 \%$ in the acute phase, $9 \%$ in the convalescent phase compared with less than $3 \%$ for healthy controls. The corresponding figures for PS PMV were 15 and $9 \%$ compared with $3 \%$ for healthy controls. Notably, for patients a clear majority of all $\mathrm{TF}^{+} \mathrm{MV}$ were $\mathrm{TF}^{+} \mathrm{PMV}$ (median $89 \%$ in the acute phase), while the opposite was the case for healthy controls (median 32\%).

\section{Non-platelet $\mathrm{TF}^{+} \mathrm{MV}$ Concentrations}

The concentrations of non-platelet $\mathrm{TF}^{+} \mathrm{MV}$ are shown in Fig. 4. In the acute phase, patients had a marginal but significant elevation of non-platelet $\mathrm{PS}^{+} \mathrm{TF}^{+} \mathrm{MV}$ compared with healthy controls, which normalized in the convalescent phase. Non-platelet $\mathrm{PS}^{-} \mathrm{TF}^{+} \mathrm{MV}$ displayed more pronounced elevations which were maintained in the convalescent phase.

\section{Correlations Between MV Populations}

As the generation mechanisms leading to circulating PS MV are unknown, we analyzed correlations between $\mathrm{PS}^{+} \mathrm{MV}$ and PS MV populations with otherwise the same surface markers. No substantial correlations were found for any of the populations, neither for patients in the acute or convalescent phase nor for healthy controls (Spearman's correlation coefficient $-0.25<\mathrm{r}<$ 0.25 for all, data not shown). For patients, marginal but 
Table 2 Concentrations of MV populations for patients in the acute and convalescent phase as compared with healthy controls

\begin{tabular}{|c|c|c|c|}
\hline & $\begin{array}{l}\text { Patients acute phase } \\
N=199\end{array}$ & $\begin{array}{l}\text { Patients conv phase } \\
N=189\end{array}$ & $\begin{array}{l}\text { Healthy controls } \\
N=53\end{array}$ \\
\hline Total MV & $25,613 \pm 3845^{* * * *}$ & $22,886 \pm 4281^{* * * *}$ & $15,036(12809-16,425)$ \\
\hline $\mathrm{PS}^{+} \mathrm{MV}$ & $20,948 \pm 3774^{* * * *}$ & $17,015 \pm 3778^{* * * *}$ & $12,716(9988-13,607)$ \\
\hline $\mathrm{PS}^{+} \mathrm{PMV}$ & $15,688 \pm 3214^{* * * *}$ & $12,807 \pm 2851^{* * * *}$ & $9364(7855-10,001)$ \\
\hline $\mathrm{PS}^{+} \mathrm{P}-\mathrm{sel}^{+} \mathrm{PMV}$ & $7118(5452-8337){ }^{* * *}$ & $4244(3326-5270)^{* * * *}$ & $1026(803-1180)$ \\
\hline $\mathrm{PS}^{+} \mathrm{TF}^{+} \mathrm{PMV}$ & $1843 \pm 500^{\text {***** }}$ & $1169 \pm 328^{* * * *}$ & $24(18-32)$ \\
\hline $\mathrm{Np} \mathrm{PS}^{+} \mathrm{TF}^{+} \mathrm{MV}$ & $163(98-218)^{* * *}$ & $112(67-152) \mathrm{ns}$ & $87(74-156)$ \\
\hline $\mathrm{PS}^{-} \mathrm{MV}$ & $4520(3210-5841)^{\text {**** }}$ & $6095(4802-6654)^{* * * *}$ & $2703(2113-3200)$ \\
\hline PS $^{-}$PMV & $3191(2331-4314)^{* * * *}$ & $4249(3457-4998)^{* * * *}$ & $1159 \pm 335$ \\
\hline PS $^{-}$P-sel ${ }^{+} \mathrm{PMV}$ & $2208(1619-2904)$ **** & $2899(2375-3445)^{* * * *}$ & $205(158-259)$ \\
\hline $\mathrm{PS}^{-} \mathrm{TF}^{+} \mathrm{PMV}$ & $468(367-579)^{* * * *}$ & $366(294-458)^{\text {***** }}$ & $32(18-44)$ \\
\hline $\mathrm{Np} \mathrm{PS}^{-} \mathrm{TF}^{+} \mathrm{MV}$ & $125(70-207)^{* * *}$ & $104(55-165)^{* * *}$ & $33(25-50)$ \\
\hline
\end{tabular}

Presented as mean \pm standard deviation or median with interquartile range (counts $\mu l^{-1}$ )

$n p$, non-platelet

$* * * p<0.0001$ compared with healthy controls significant negative correlations were found for $\mathrm{PS}^{+} \mathrm{PMV}$ and $\mathrm{PS}^{-} \mathrm{PMV}$, respectively, $\mathrm{PS}^{+} \mathrm{P}-$ selectin ${ }^{+} \mathrm{PMV}$ and $\mathrm{PS}^{-} \mathrm{P}-$ selectin ${ }^{+} \mathrm{PMV}$; Spearman's correlation coefficient - $(0.15-0.19)$ data not shown.

\section{Concentrations Versus Clinical Factors}

Comparing patients with IS and TIA as the index event, no significant differences were found in MV subpopulation concentrations measured in the acute phase. In the convalescent phase, patients with TIA had marginally lower $\mathrm{PS}^{+} \mathrm{PMV}$ than those with IS as index event (relative difference less than $10 \%$ ); for other MV subpopulations there were no significant differences. There were no significant differences in MV concentrations depending on treatment (data not shown). There were no correlations between stroke severity measured by NIHSS points and MV concentrations.

\section{Prospective Analysis of MV Associations with Outcomes}

\section{Variable Screening and Univariate Analysis}

Univariate variable screening with descriptive statistics and Kaplan-Meier analysis based on median split was negative for a majority of the MV populations studied versus all outcomes. This included the primary candidate risk markers: $\mathrm{PS}^{+} \mathrm{P}-$ selectin ${ }^{+} \mathrm{PMV}$, thought to reflect "true" platelet activation, and $\mathrm{PS}^{+} \mathrm{TF}^{+} \mathrm{PMV}$, the dominant $\mathrm{TF}^{+} \mathrm{MV}$ population. Variable screening identified four MV populations with possible associations with outcomes; they are shown in Fig. 5. In the acute phase, $\mathrm{PS}^{-} \mathrm{TF}^{+} \mathrm{PMV}$ concentrations above median tended to be associated with an increased risk of primary outcome, see Fig. 5a. In contrast, $\mathrm{PS}^{+} \mathrm{PMV}$ above median in the acute phase appeared associated with an unexpected reduced risk for primary outcome, see Fig. 5b. In the convalescent phase, two populations showed possible associations with outcome PS P-sel ${ }^{+} \mathrm{PMV}$ above median tended to be associated with a reduced risk of primary outcome, see Fig. 5c. Further, non-platelet $\mathrm{PS}^{+} \mathrm{TF}^{+} \mathrm{MV}$ tended to be associated with a reduced risk of the secondary outcome recurrent IS, see Fig. 5d. The number of events and patients analyzed for the respective populations are specified in Table 3 .

None of the studied MV-populations was associated with all-cause mortality.

\section{Acute-Phase Multivariate Analysis}

A first step of the multivariate analysis was to determine whether acute-phase $\mathrm{PS}^{-} \mathrm{TF}^{+} \mathrm{PMV}$ and $\mathrm{PS}^{+} \mathrm{PMV}$ were independently associated with risk for primary outcome. Unexpectedly, correlation analysis showed that $\mathrm{PS}^{-} \mathrm{TF}^{+} \mathrm{PMV}$ and $\mathrm{PS}^{+} \mathrm{PMV}$ in the acute phase were moderately negatively correlated, Spearman's correlation coefficient $r=-0.35$ $(p<0.0001)$. These two variables were therefore not included in the same multivariate analysis.

A multivariate forward stepwise Cox regression model, adjusted for cardiovascular risk factors (in order of importance as established in "Cohort Characteristics and OutcomeS18") was performed for $\mathrm{PS}^{-} \mathrm{TF}^{+} \mathrm{PMV}$ in the acute phase. The results are presented in Table 4. $\mathrm{PS}^{-} \mathrm{TF}^{+} \mathrm{PMV}$ was found to be a predictor of primary outcome after adjusting for diabetes, reduced kidney function, age, and sex, with HR 1.86 (1.04$3.31, p=0.036$ ).

The same model for PS ${ }^{+} \mathrm{PMV}$ in the acute phase resulted in the association between $\mathrm{PS}^{+} \mathrm{PMV}$ and primary outcome becoming increasingly non-significant after adjustment for cardiovascular risk factors $(p=0.212$ in the final step of the model, data not shown). 

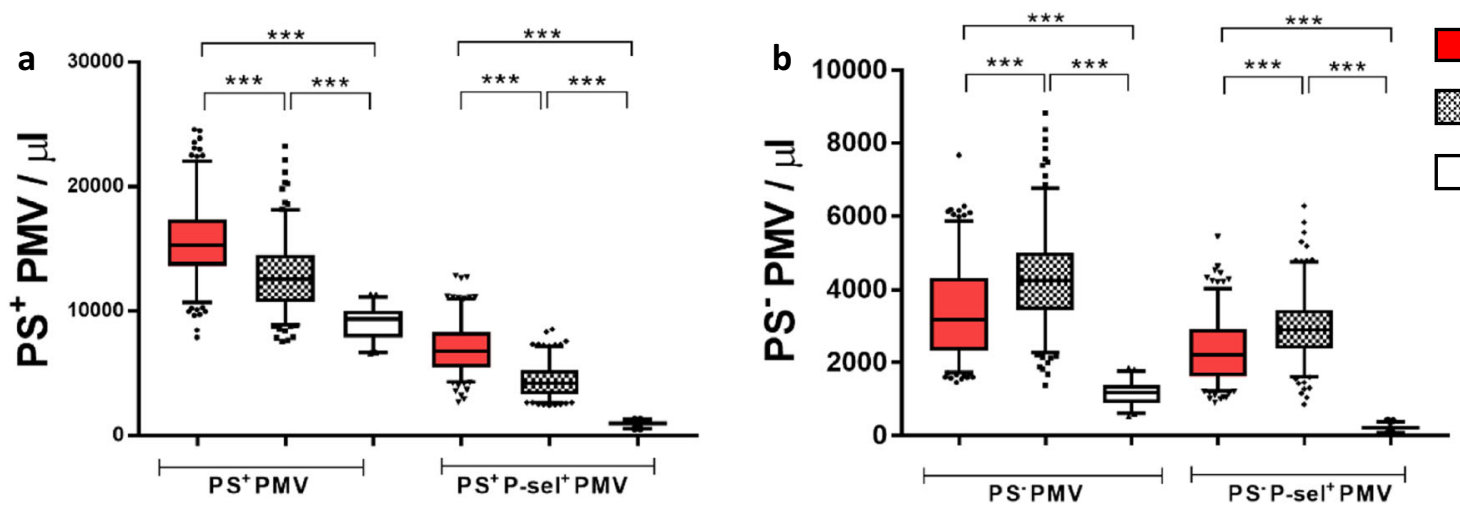

Fig. 2 a Concentrations of $\mathrm{PS}^{+} \mathrm{PMV}$ and $\mathrm{PS}^{+} \mathrm{P}$-selectin ${ }^{+} \mathrm{PMV}$ and $\mathbf{b} \mathrm{PS}^{-} \mathrm{PMV}$ and $\mathrm{PS}^{-} \mathrm{P}$-selectin ${ }^{+} \mathrm{PMV}$. Red, patients in the acute phase; gray, patients in the convalescent phase; and white, healthy controls. ${ }^{* * *} p<0.0001$. Box, 25-75\%; whiskers, $5-95 \%$

\section{Convalescent Phase Multivariate Analysis}

In the multivariate analysis for convalescent phase variables, neither the association between PS ${ }^{-}$-selectin ${ }^{+} \mathrm{PMV}$ and primary outcome nor the association between non-platelet $\mathrm{PS}^{+} \mathrm{TF}^{+} \mathrm{MV}$ and recurrent IS was significant after adjustment for cardiovascular risk factors.

\section{Discussion}

In one of the first prospective studies to map and subtype $\mathrm{PMV}$ and $\mathrm{TF}^{+} \mathrm{MV}$ both positive and negative for phosphatidylserine (PS) in patients with IS/TIA, we show elevations of not only PS-positive but also PS-negative populations, which were maintained in the convalescent phase. In agreement with our hypothesis, $\mathrm{PS}^{+} \mathrm{P}$-selectin ${ }^{+} \mathrm{PMV}$ showed more pronounced elevations compared with healthy controls than $\mathrm{PS}^{+} \mathrm{PMV}$ overall. Other results were unanticipated and contradicted original hypotheses. The main findings were:

1. Levels of $\mathrm{TF}^{+} \mathrm{MV}$ were unexpectedly high in patients and the vast majority co-expressed the platelet-specific marker GPIIb.
2. The primary biomarker candidates, $\mathrm{PS}^{+} \mathrm{P}-$ selectin $^{+} \mathrm{PMV}$, reflecting platelet activation, and $\mathrm{PS}^{+} \mathrm{TF}^{+} \mathrm{PMV}$, the dominant $\mathrm{TF}^{+} \mathrm{MV}$ population, were not associated with outcome, despite having pronounced elevations in the acute and convalescent phase.

3. Only a few unexpected MV populations showed possible associations with outcome, two of which were PS negative and three of which tended to be associated with reduced risk.

4. $\mathrm{PS}^{+}$and $\mathrm{PS}^{-} \mathrm{MV}$ populations of the same type had few commonalities; they lacked correlations, had partly differing time profile after IS/TIA and differed in their associations with risk.

\section{Baseline $\mathrm{TF}^{+} \mathrm{MV}$ Concentrations}

Levels of $\mathrm{TF}^{+} \mathrm{MV}$ co-expressing the platelet marker GPIIb $\left(\mathrm{TF}^{+} \mathrm{PMV}\right)$ were unexpectedly high in patients and exceedingly rare in healthy controls. In contrast, levels of nonplatelet $\mathrm{TF}^{+} \mathrm{MV}$ were low, with limited elevations in patients compared with healthy controls. Thus, platelets contribute substantially to the generation of circulating $\mathrm{TF}^{+} \mathrm{MV}$ after IS/TIA. Furthermore, levels of $\mathrm{TF}^{+} \mathrm{PMV}$ were about one order of magnitude higher after IS/TIA
Fig. 3 Concentrations of $\mathrm{PS}^{+} \mathrm{TF}^{+} \mathrm{PMV}$ and $\mathrm{PS}^{-} \mathrm{TF}^{+} \mathrm{PMV}$. Red, patients in the acute phase; gray, patients in the convalescent phase; and white, healthy controls. *** $p<0.0001$. Box 25-75\%; whiskers, 5-95\%

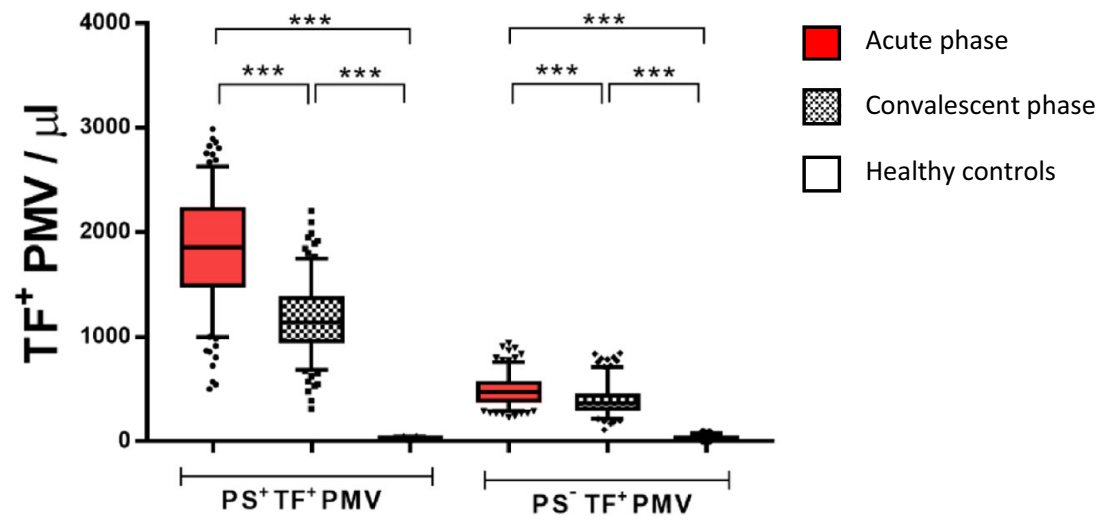


Fig. 4 Concentrations of nonplatelet (np) $\mathrm{PS}^{+} \mathrm{TF}^{+} \mathrm{MV}$ and $\mathrm{PS}^{-} \mathrm{TF}^{+} \mathrm{MV}$. Red, patients in the acute phase; gray, patients in the convalescent phase; white, healthy controls. $* * * p<0.0001$; NS, non-significant. Box, 25$75 \%$; whiskers, $5-95 \%$

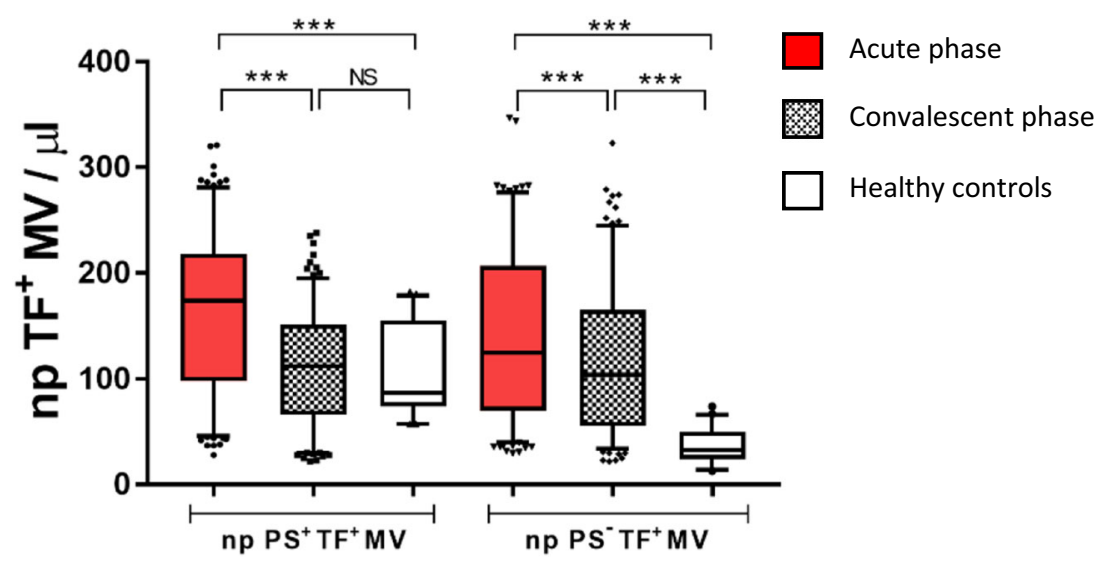

compared with levels found for patients with ACS by our group using a similar MV protocol [21], i.e., $\mathrm{TF}^{+} \mathrm{PMV}$ generation appears substantially higher after cerebral compared with myocardial ischemia. Underlying mechanisms are unknown, but certain aspects should be mentioned. The specific central nervous system (CNS)-induced acutephase response after IS/TIA or ischemia/reperfusion injury enhances chemokine expression in the liver, neutrophil mobilization, and activation of monocytes, Kupffer cells, and macrophages [27]. This may induce TF expression particularly in monocytic cells; TF could subsequently be taken up by platelets or transferred to platelets by cell-cell interactions. Another possible source of TF could be the ischemic/post-ischemic brain itself. Astrocytes in the brain are rich in TF, with particularly high levels close to perivascular spaces and subependymally [43]. High levels of circulating $\mathrm{TF}^{+} \mathrm{PMV}$ levels were previously found by our group in the acute phase of traumatic brain injury [44]. Astrocyte damage and/or activation after IS/TIA may result in leakage of TF to the blood, either by increased permeability of the blood-brain barrier or by clearance through the recently identified glymphatic and meningeal lymphatic systems [45]. Independent of underlying mechanisms, $\mathrm{TF}^{+} \mathrm{PMV}$ emerge as a promising biomarker for cerebral ischemia, as levels remain elevated for at least 1 month after IS/TIA.
Fig. 5 Univariate Kaplan-Meier curves for recurrent ischemic events versus respective MV concentrations above (red curves) and below median (black curves). a Primary outcome for patients with $\mathrm{PS}^{-} \mathrm{TF}^{+} \mathrm{PMV}$ above and below median in the acute phase. $\mathbf{b}$ Primary outcome for $\mathrm{PS}^{+} \mathrm{PMV}$ above and below median in the acute phase. c Primary outcome for patients with $\mathrm{PS}^{-} \mathrm{P}-$ sel $^{+} \mathrm{PMV}$ above and below median in the convalescent phase. d Secondary outcome recurrent IS for patients with non-platelet $\mathrm{PS}^{+} \mathrm{TF}^{+} \mathrm{MV}$ above and below median in the convalescent phase
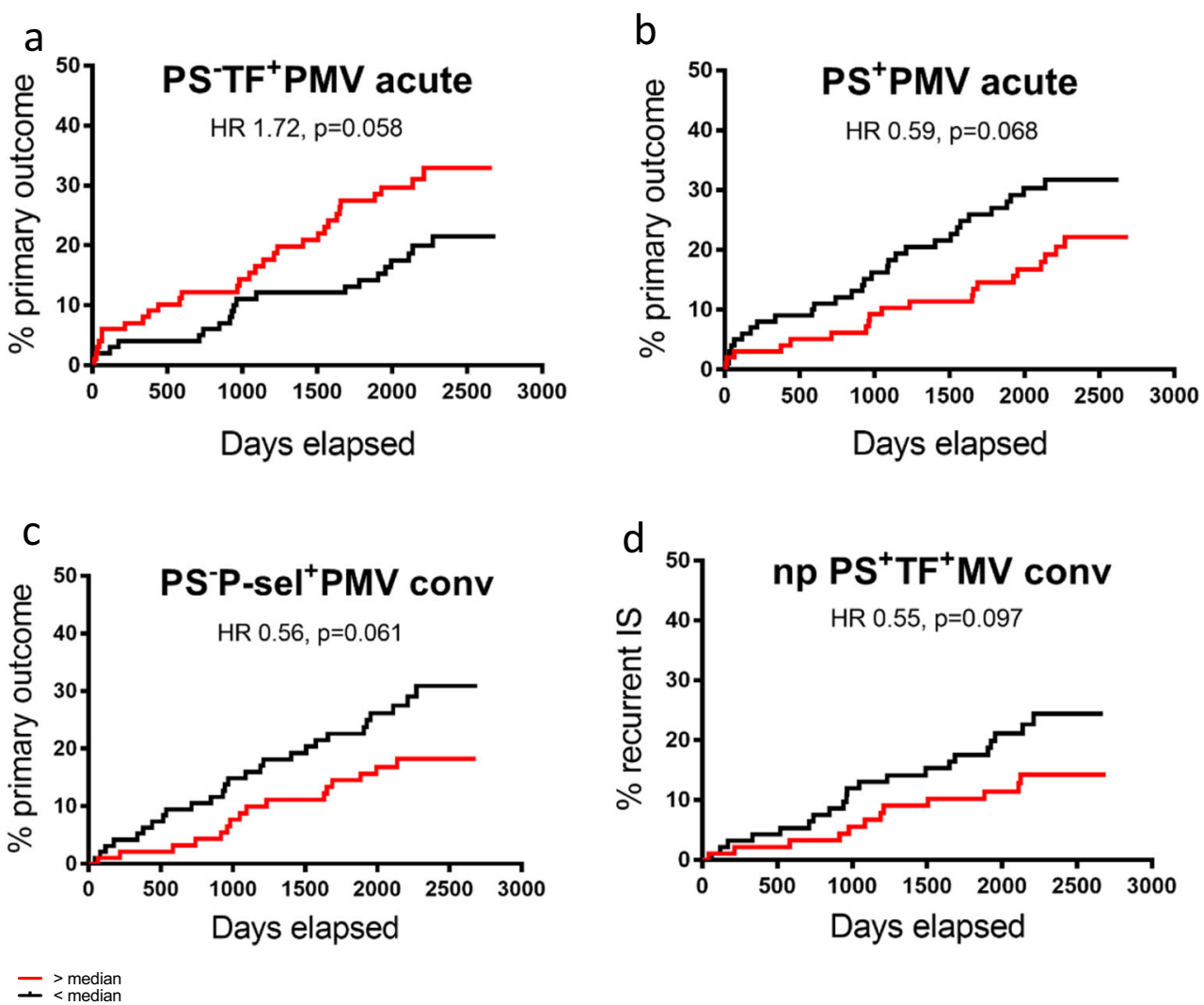

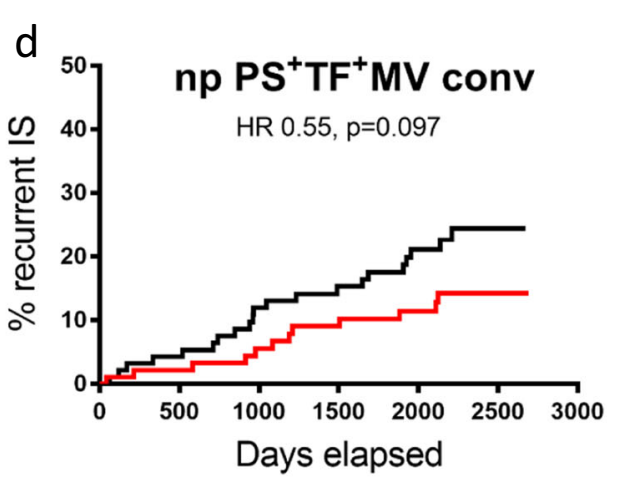




\section{Associations Between MV Populations and Outcome}

The prospective analysis disproved the original hypothesis that $\mathrm{PS}^{+} \mathrm{P}$-selectin ${ }^{+} \mathrm{PMV}$ and/or $\mathrm{PS}^{+} \mathrm{TF}^{+} \mathrm{PMV}$ would be associated with poor outcome. Instead, these populations were neutral with respect to risk, despite showing pronounced elevations in both the acute and convalescent phase. The result illustrates the limitation of cross-sectional studies in evaluating $\mathrm{MV}$ as candidate biomarkers. In our previous study on ACS patients, $\mathrm{PS}^{+} \mathrm{P}$-selectin ${ }^{+} \mathrm{PMV}$ nearly normalized and $\mathrm{PS}^{+} \mathrm{TF}^{+} \mathrm{PMV}$ decreased by half after 6 months [21]; this could be the case also after IS/TIA, which could contribute a lack of association with long-term outcome. It cannot be excluded that $\mathrm{PS}^{+} \mathrm{P}$-selectin ${ }^{+} \mathrm{PMV}$ and $\mathrm{PS}^{+} \mathrm{TF}^{+} \mathrm{PMV}$ have associations with early recurrent events that the present study does not have the power to reveal. However, at present $\mathrm{PS}^{+} \mathrm{P}-$ selectin ${ }^{+} \mathrm{PMV}$ and $\mathrm{PS}^{+} \mathrm{TF}^{+} \mathrm{PMV}$ do not appear to be promising biomarkers of long-term risk after IS/TIA, despite theoretical appeal.

The MV populations identified as having possible associations with long-term outcome were unexpected, as were the risk relations found. The only population with increased risk was PS negative; $\mathrm{PS}^{-} \mathrm{TF}^{+} \mathrm{PMV}$ were significantly associated with primary outcome after adjustment for CVD risk factors. Since the generation mechanisms, target cells and clearance of $\mathrm{PS}^{-} \mathrm{TF}^{+} \mathrm{PMV}$ are unknown, it is unclear how this population mediates risk. Interestingly, a recent study on SLE patients showed PS PMV to have stronger association to disease activity than $\mathrm{PS}^{+} \mathrm{PMV}$ populations [46], supporting the notion that $\mathrm{PS}^{-} \mathrm{MV}$ may have a role in pathophysiology. It would thus be of interest to characterize $\mathrm{PS}^{-} \mathrm{TF}^{+} \mathrm{PMV}$ further.

Three MV populations tended to be associated with reduced risks in univariate analysis: $\mathrm{PS}^{+} \mathrm{PMV}$ in the acute phase versus primary outcome, $\mathrm{PS}^{-} \mathrm{P}$-selectin ${ }^{+} \mathrm{PMV}$ in the convalescent phase versus primary outcome and nonplatelet $\mathrm{PS}^{+} \mathrm{TF}^{+} \mathrm{MV}$ in the convalescent phase versus recurrent IS. Adjustment for CVD risk factors resulted in non-significant HR for all. The limited number of events may have contributed to the lack of significance, as Kaplan-Meier curves showed consistent separation over time-significance may have been reached in a larger study. In general, MV are studied for their proinflammatory or procoagulant effects, and the concept that certain MV populations could be protective has so far received limited attention. However, PMV have been reported to mediate tissue repair and vascular remodeling, e.g., stimulating angiogenesis [10]. It was recently shown that topical application of PMV to the ischemic brain in a mouse model of ischemic stroke resulted in enhanced angiogenesis and neurogenesis, improving neurological outcome [47]. Such effects could explain the apparent positive effect observed.

\section{Comparison of $\mathrm{PS}^{+}$and $\mathrm{PS}^{-} \mathrm{MV}$ Populations}

So far, $\mathrm{PS}^{-} \mathrm{MV}$ populations have received little attention, and many studies enumerate only $\mathrm{PS}^{+} \mathrm{MV}$ or total $\mathrm{MV}$ without a separate marker for PS. It is debated whether MV identified as PS negative completely lack PS or express PS at concentrations too low for detection with annexin $\mathrm{V}$, the marker most commonly used $[35,40]$. We have used the more sensitive PS-marker lactadherin [40], still finding a substantial proportion of MV to be PS negative. It has been proposed that PS-negative MV could be PS-positive at formation, with PS subsequently binding endogenous molecules such as lactadherin or $\beta 2$-glycoprotein-1, which may mask PS epitopes $[48,49]$. It has also been suggested the PS-negative MV would remain longer in the circulation, not being subjected to the same clearance mechanisms as PS-positive MV [50, 51]. High generation/high clearance of PS-positive MV combined with low generation/low clearance of PS-negative MV would be consistent both with PS-positive MV being the dominant generation mechanism and the relatively high number of circulating PS-negative MV found, e.g., by Arraud. Notably, our results provide little support for the notion that PS-positive and PS-negative MV subtypes are "two sides of the same coin." If generation mechanisms were common, at least for healthy controls sampled under steadystate conditions, one would expect positive correlations between PS-positive and PS-negative MV of the same type. We found no important correlations for any of the groups tested, and the weak correlations in patients were negative. Further, the correlation between $\mathrm{PS}^{+} \mathrm{PMV}$ and $\mathrm{PS}^{-} \mathrm{TF}^{+} \mathrm{PMV}$ was clearly negative. For patients, the time profiles differed when comparing $\mathrm{PS}^{+} / \mathrm{PS}^{-} \mathrm{PMV}$ respectively with $\mathrm{P}$ selection ${ }^{+} \mathrm{PMV}$. Also, associations between $\mathrm{PS}^{+} / \mathrm{PS}^{-} \mathrm{MV}$ subpopulations and risk differed. Together, our results suggest important differences in circulating $\mathrm{PS}^{+} \mathrm{MV}$ and $\mathrm{PS}^{-} \mathrm{MV}$ subtypes, which may involve generation, binding to target cells and/or clearance. With respect to $\mathrm{PS}^{+} / \mathrm{PS}^{-} \mathrm{PMV}$, it is increasingly recognized that platelets adopt different phenotypes at activation, which are either positive or negative for PS [52, 53]. If $\mathrm{PS}^{+}$and $\mathrm{PS}^{-} \mathrm{PMV}$ are released from different and complementary platelet phenotypes, it would explain negative correlations. Further study of the nature and generation of $\mathrm{PS}^{-} \mathrm{MV}$ is warranted. From a biomarker perspective, our results suggest that $\mathrm{PS}^{+}$and $\mathrm{PS}^{-} \mathrm{MV}$ subpopulations should be considered separate entities and should be enumerated separately.

\section{Conclusions}

In one of the larger clinical studies on MV after IS/TIA, $\mathrm{TF}^{+} \mathrm{PMV}$ were found strongly elevated in both the acute and convalescent phase and may be promising markers of cerebral 
Table 3 Result of univariate variable screening with KaplanMeier analysis based on median split with hazard ratio (HR) calculated by univariate Cox regression

\begin{tabular}{|c|c|c|c|c|c|c|}
\hline & \multicolumn{3}{|c|}{ Primary outcome } & \multicolumn{3}{|c|}{ Recurrent IS } \\
\hline & HR & $N$ & $p$ (log rank) & HR & $N$ & $p(\log$ rank $)$ \\
\hline \multicolumn{7}{|l|}{ Acute phase values } \\
\hline $\mathrm{PS}^{-} \mathrm{TF}^{+} \mathrm{PMV}$ above median & 1.72 & $50 / 199$ & 0.058 & & & \\
\hline $\mathrm{PS}^{+} \mathrm{PMV}$ above median & 0.59 & $50 / 199$ & 0.068 & & & \\
\hline \multicolumn{7}{|l|}{ Convalescent phase values } \\
\hline PS $^{-} \mathrm{P}-\mathrm{sel}^{+} \mathrm{PMV}$ above median & 0.56 & $43 / 189$ & 0.061 & & & \\
\hline $\mathrm{PS}^{+} \mathrm{TF}^{+} \mathrm{GPIIb}^{-} \mathrm{MP}$ above median & & & & 0.55 & $33 / 188$ & 0.097 \\
\hline
\end{tabular}

Variables with $p<0.1$ for difference by log rank test for primary outcome and secondary outcome ischemic stroke (IS), respectively

$N$, number of cases of with event out of total number tested ischemia. However, only the minor population PS-negative $\mathrm{TF}^{+} \mathrm{PMV}$ was positively associated with risk of new ischemic events. Several MV populations tended to be associated with reduced risk of poor outcome, suggesting possible protective effects. Our results illustrate that prospective studies of MV subtypes in relation to outcome has the potential to reveal pathological or indeed protective patterns of cell activation after IS/TIA.

\section{Limitations}

Patients in the cohort differed in treatments that may influence MV generation, in particular, antithrombotic/ antiplatelet treatment. Aspirin, the most common treatment, and warfarin are considered to have a limited influence on overall PMV levels; clopidogrel (given to a minority of patients) has been found to reduce PMV overall [54]. Aspirin (COX-1 inhibition) and clopidogrel ( $\mathrm{P}^{2} \mathrm{Y}_{12}$ inhibition) also differ in their effect on platelet-leukocyte interactions and off-target pro- and anti-inflammatory effects $[55,56]$. The study was not designed or powered to address these issues, but univariate analysis did not show significant differences in MV concentrations depending on treatment received.

Table 4 Multivariate Cox regression model for $\mathrm{PS}^{-} \mathrm{TF}^{+} \mathrm{PMV}$ in the acute phase versus primary outcome, adjusted for cardiovascular risk factors

\begin{tabular}{|c|c|c|c|}
\hline Variable & HR & HR CI & $p$ value \\
\hline $\mathrm{PS}^{-} \mathrm{TF}^{+} \mathrm{PMV}$ above median & 1.86 & $1.04-3.31$ & 0.036 \\
\hline Diabetes at inclusion & 2.10 & $1.06-4.12$ & 0.032 \\
\hline 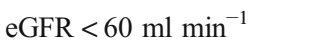 & 2.03 & $1.03-4.00$ & 0.042 \\
\hline Age at inclusion $>70$ years & 1.65 & $0.86-3.18$ & 0.131 \\
\hline Male sex & 2.27 & $1.22-4.24$ & 0.010 \\
\hline
\end{tabular}

$H R$, hazard ratio; $C I, 95 \%$ confidence interval; $e G F R$, estimated glomerular filtration rate
Pre-analytical sample handling influences MV concentrations. We used PPP centrifuged at $2000 \times g$ for $20 \mathrm{~min}$ as the starting material, an established method at the time of blood sampling (2007-2009). Since 2013, ISTH recommends double centrifugation $(2500 \times \mathrm{g}$ for $15 \mathrm{~min} \times 2)$ before freezing to exclude spurious PMV from in vitro platelet activation [57]. As we used phalloidin to confirm low levels of residual cell fragments [39], we expect the error due to centrifugation to be limited. The sensitivity of flow cytometry to small MV is another limitation; we would estimate the lower limit of detection to be in the range $250-300 \mu \mathrm{m}$, i.e., just above the median size found for spherical MV in healthy in plateletfree plasma [36]. While smaller MV may be missed, we expect limited detection of exosomes, which are not the topic of this study. Also, large MV may have stronger clinical relevance while large PMV had a stronger activating effect on neutrophils and endothelial cells in vitro than small in one study [58], and a recent study found $\mathrm{TF}^{+} \mathrm{MV}$ to be in the larger size range [59].

Acknowledgments The authors gratefully acknowledge the technical assistance of Katherina Aguilera and the assistance of research nurses Eva Isaksson and Helena Kumpulainen.

Funding Information Open access funding provided by Karolinska Institute. The study was partly funded by the Swedish Stroke Association (Stroke Riksförbundet), the Regional Agreement on Medical Training and Clinical Research (ALF) between Stockholm County Council and Karolinska Institutet, and the Foundation for Coagulation Research at Karolinska Institutet, which are all gratefully acknowledged.

\section{Compliance with Ethical Standards}

Conflict of Interest The authors declare that they have no conflict of interest.

Ethical Approval The study complied with the declaration of Helsinki and was approved by the local Ethics Review Board at Karolinska Institutet (EPN 2007/386-81 with addendum 2013/2011-32). 
Informed Consent Informed consent was obtained from all participants in the study.

Open Access This article is licensed under a Creative Commons Attribution 4.0 International License, which permits use, sharing, adaptation, distribution and reproduction in any medium or format, as long as you give appropriate credit to the original author(s) and the source, provide a link to the Creative Commons licence, and indicate if changes were made. The images or other third party material in this article are included in the article's Creative Commons licence, unless indicated otherwise in a credit line to the material. If material is not included in the article's Creative Commons licence and your intended use is not permitted by statutory regulation or exceeds the permitted use, you will need to obtain permission directly from the copyright holder. To view a copy of this licence, visit http://creativecommons.org/licenses/by/4.0/.

\section{References}

1. DALYs GBD, Collaborators H. Global, regional, and national disability-adjusted life-years (DALYs) for 359 diseases and injuries and healthy life expectancy (HALE) for 195 countries and territories, 1990-2017: a systematic analysis for the global burden of disease study 2017. Lancet. 2018;392(10159):1859-922.

2. Grau AJ, Ruf A, Vogt A, Lichy C, Buggle F, Patscheke H, et al. Increased fraction of circulating activated platelets in acute and previous cerebrovascular ischemia. Thromb Haemost. 1998;80(2): 298-301.

3. Meiklejohn DJ, Vickers MA, Morrison ER, Dijkhuisen R, Moore I, Urbaniak SJ, et al. In vivo platelet activation in atherothrombotic stroke is not determined by polymorphisms of human platelet glycoprotein IIIa or Ib. Br J Haematol. 2001;112(3):621-31.

4. Garlichs CD, Kozina S, Fateh-Moghadam S, Handschu R, Tomandl B, Stumpf C, et al. Upregulation of CD40-CD40 ligand (CD154) in patients with acute cerebral ischemia. Stroke. 2003;34(6):1412-8.

5. Wolf $P$. The nature and significance of platelet products in human plasma. Br J Haematol. 1967;13(3):269-88.

6. Sims PJ, Wiedmer T, Esmon CT, Weiss HJ, Shattil SJ. Assembly of the platelet prothrombinase complex is linked to vesiculation of the platelet plasma membrane. Studies in Scott syndrome: an isolated defect in platelet procoagulant activity. J Biol Chem. 1989;264(29): 17049-57.

7. Sinauridze EI, Kireev DA, Popenko NY, Pichugin AV, Panteleev MA, Krymskaya OV, et al. Platelet microparticle membranes have 50 - to 100 -fold higher specific procoagulant activity than activated platelets. Thromb Haemost. 2007;97(3):425-34.

8. Gilbert GE, Sims PJ, Wiedmer T, Furie B, Furie BC, Shattil SJ. Platelet-derived microparticles express high affinity receptors for factor VIII. J Biol Chem. 1991;266(26):17261-8.

9. Hoffman M, Monroe DM, Roberts HR. Coagulation factor IXa binding to activated platelets and platelet-derived microparticles: a flow cytometric study. Thromb Haemost. 1992;68(1):74-8.

10. Burnouf T, Goubran HA, Chou ML, Devos D, Radosevic M. Platelet microparticles: detection and assessment of their paradoxical functional roles in disease and regenerative medicine. Blood Rev. 2014;28(4):155-66.

11. Zaldivia MTK, McFadyen JD, Lim B, Wang X, Peter K. Plateletderived microvesicles in cardiovascular diseases. Front Cardiovasc Med. 2017;4:74

12. Boilard E, Duchez AC, Brisson A. The diversity of platelet microparticles. Curr Opin Hematol. 2015;22(5):437-44.

13. Ponomareva AA, Nevzorova TA, Mordakhanova ER, Andrianova IA, Rauova L, Litvinov RI, et al. Intracellular origin and ultrastructure of platelet-derived microparticles. J Thromb Haemost. 2017;15(8):1655-67.

14. Perez-Pujol S, Marker PH, Key NS. Platelet microparticles are heterogeneous and highly dependent on the activation mechanism: studies using a new digital flow cytometer. Cytometry A. 2007;71(1):38-45.

15. Drake TA, Morrissey JH, Edgington TS. Selective cellular expression of tissue factor in human tissues. Implications for disorders of hemostasis and thrombosis. Am J Pathol. 1989;134(5):1087-97.

16. Giesen PL, Rauch U, Bohrmann B, Kling D, Roque M, Fallon JT, et al. Blood-borne tissue factor: another view of thrombosis. Proc Natl Acad Sci U S A. 1999;96(5):2311-5.

17. Falati S, Liu Q, Gross P, Merrill-Skoloff G, Chou J, Vandendries E, et al. Accumulation of tissue factor into developing thrombi in vivo is dependent upon microparticle P-selectin glycoprotein ligand 1 and platelet P-selectin. J Exp Med. 2003;197(11):1585-98.

18. Owens AP 3rd, Mackman N. Microparticles in hemostasis and thrombosis. Circ Res. 2011;108(10):1284-97.

19. Morel O, Morel N, Freyssinet JM, Toti F. Platelet microparticles and vascular cells interactions: a checkpoint between the haemostatic and thrombotic responses. Platelets. 2008;19(1):9-23.

20. Osterud B, Bjorklid E. Tissue factor in blood cells and endothelial cells. Front Biosci (Elite Ed). 2012;4:289-99.

21. Skeppholm M, Mobarrez F, Malmqvist K, Wallen H. Plateletderived microparticles during and after acute coronary syndrome. Thromb Haemost. 2012;107(6):1122-9.

22. Muller I, Klocke A, Alex M, Kotzsch M, Luther T, Morgenstern E, et al. Intravascular tissue factor initiates coagulation via circulating microvesicles and platelets. FASEB J. 2003;17(3):476-8.

23. Rauch U, Bonderman D, Bohrmann B, Badimon JJ, Himber J, Riederer MA, et al. Transfer of tissue factor from leukocytes to platelets is mediated by CD15 and tissue factor. Blood. 2000;96(1):170-5.

24. Del Conde I, Shrimpton CN, Thiagarajan P, Lopez JA. Tissuefactor-bearing microvesicles arise from lipid rafts and fuse with activated platelets to initiate coagulation. Blood. 2005;106(5): 1604-11.

25. Engelmann B, Massberg S. Thrombosis as an intravascular effector of innate immunity. Nat Rev Immunol. 2013;13(1):34-45.

26. Jackson SP, Darbousset R, Schoenwaelder SM. Thromboinflammation: challenges of therapeutically targeting coagulation and other host defense mechanisms. Blood. 2019;133(9):906-18.

27. Catania A, Lonati C, Sordi A, Gatti S. Detrimental consequences of brain injury on peripheral cells. Brain Behav Immun. 2009;23(7): 877-84.

28. Lee YJ, Jy W, Horstman LL, Janania J, Reyes Y, Kelley RE, et al. Elevated platelet microparticles in transient ischemic attacks, lacunar infarcts, and multiinfarct dementias. Thromb Res. 1993;72(4): 295-304.

29. Cherian P, Hankey GJ, Eikelboom JW, Thom J, Baker RI, McQuillan A, et al. Endothelial and platelet activation in acute ischemic stroke and its etiological subtypes. Stroke. 2003;34(9): 2132-7.

30. Chiva-Blanch G, Suades R, Crespo J, Pena E, Padro T, JimenezXarrie E, et al. Microparticle shedding from neural progenitor cells and vascular compartment cells is increased in ischemic stroke. PLoS One. 2016;11(1):e0148176.

31. Switonska M, Slomka A, Sinkiewicz W, Zekanowska E. Tissuefactor-bearing microparticles (MPs-TF) in patients with acute ischaemic stroke: the influence of stroke treatment on MPs-TF generation. Eur J Neurol. 2015;22(2):395-401e28-9.

32. Flaumenhaft R, Dilks JR, Richardson J, Alden E, Patel-Hett SR, Battinelli E, et al. Megakaryocyte-derived microparticles: direct visualization and distinction from platelet-derived microparticles. Blood. 2009;113(5):1112-21. 
33. van der Zee PM, Biro E, Ko Y, de Winter RJ, Hack CE, Sturk A, et al. P-selectin- and CD63-exposing platelet microparticles reflect platelet activation in peripheral arterial disease and myocardial infarction. Clin Chem. 2006;52(4):657-64.

34. Morel O, Jesel L, Freyssinet JM, Toti F. Cellular mechanisms underlying the formation of circulating microparticles. Arterioscler Thromb Vasc Biol. 2011;31(1):15-26.

35. Ridger VC, Boulanger CM, Angelillo-Scherrer A, Badimon L, Blanc-Brude O, Bochaton-Piallat ML, et al. Microvesicles in vascular homeostasis and diseases. Position paper of the European Society of Cardiology (ESC) working group on atherosclerosis and vascular biology. Thromb Haemost. 2017;117(7):1296-316.

36. Arraud N, Linares R, Tan S, Gounou C, Pasquet JM, Mornet S, et al. Extracellular vesicles from blood plasma: determination of their morphology, size, phenotype and concentration. J Thromb Haemost. 2014;12(5):614-27.

37. Doliwa Sobocinski P, Anggardh Rooth E, Frykman Kull V, von Arbin M, Wallen H, Rosenqvist M. Improved screening for silent atrial fibrillation after ischaemic stroke. Europace. 2012;14(8): 1112-6.

38. Rooth E, Sobocinski-Doliwa P, Antovic J, Frykman Kull V, Von Arbin M, Rosenqvist M, et al. Thrombin generation in acute cardioembolic and non-cardioembolic ischemic stroke. Scand J Clin Lab Invest. 2013;73(7):576-84.

39. Mobarrez F, Antovic J, Egberg N, Hansson M, Jorneskog G, Hultenby K, et al. A multicolor flow cytometric assay for measurement of platelet-derived microparticles. Thromb Res. 2010;125(3): e110-6.

40. Dasgupta SK, Guchhait P, Thiagarajan P. Lactadherin binding and phosphatidylserine expression on cell surface-comparison with annexin A5. Transl Res. 2006;148(1):19-25.

41. Mobarrez F, He S, Broijersen A, Wiklund B, Antovic A, Antovic J, et al. Atorvastatin reduces thrombin generation and expression of tissue factor, P-selectin and GPIIIa on platelet-derived microparticles in patients with peripheral arterial occlusive disease. Thromb Haemost. 2011;106(2):344-52.

42. Badrnya S, Baumgartner R, Assinger A. Smoking alters circulating plasma microvesicle pattern and microRNA signatures. Thromb Haemost. 2014;112(1):128-36.

43. Flossel C, Luther T, Muller M, Albrecht S, Kasper M. Immunohistochemical detection of tissue factor (TF) on paraffin sections of routinely fixed human tissue. Histochemistry. 1994;101(6):449-53.

44. Nekludov M, Mobarrez F, Gryth D, Bellander BM, Wallen H. Formation of microparticles in the injured brain of patients with severe isolated traumatic brain injury. J Neurotrauma. 2014;31(23):1927-33.

45. Louveau A, Plog BA, Antila S, Alitalo K, Nedergaard M, Kipnis J. Understanding the functions and relationships of the glymphatic system and meningeal lymphatics. J Clin Invest. 2017;127(9): 3210-9.

46. Fortin PR, Cloutier N, Bissonnette V, Aghdassi E, Eder L, Simonyan D, et al. Distinct subtypes of microparticle-containing immune complexes are associated with disease activity, damage, and carotid intima-media thickness in systemic lupus erythematosus. J Rheumatol. 2016;43(11):2019-25.
47. Hayon Y, Dashevsky O, Shai E, Brill A, Varon D, Leker RR. Platelet microparticles induce angiogenesis and neurogenesis after cerebral ischemia. Curr Neurovasc Res. 2012;9(3):185-92.

48. Mobarrez F, Gunnarsson I, Svenungsson E. Altered beta2glycoprotein I expression on microparticles in the presence of antiphospholipid antibodies. J Thromb Haemost. 2017;15(9): 1799-806.

49. Bergen K, Mobarrez F, Jorneskog G, Wallen H, Tehrani S. Phosphatidylserine expressing microvesicles in relation to microvascular complications in type 1 diabetes. Thromb Res. 2018;172: $158-64$.

50. Dasgupta SK, Abdel-Monem H, Niravath P, Le A, Bellera RV, Langlois $\mathrm{K}$, et al. Lactadherin and clearance of platelet-derived microvesicles. Blood. 2009;113(6):1332-9.

51. Dasgupta SK, Le A, Chavakis T, Rumbaut RE, Thiagarajan P. Developmental endothelial locus-1 (Del-1) mediates clearance of platelet microparticles by the endothelium. Circulation. 2012;125(13):1664-72

52. Munnix IC, Kuijpers MJ, Auger J, Thomassen CM, Panizzi P, van Zandvoort MA, et al. Segregation of platelet aggregatory and procoagulant microdomains in thrombus formation: regulation by transient integrin activation. Arterioscler Thromb Vasc Biol. 2007;27(11):2484-90.

53. Agbani EO, van den Bosch MT, Brown E, Williams CM, Mattheij NJ, Cosemans JM, et al. Coordinated membrane ballooning and procoagulant spreading in human platelets. Circulation. 2015;132(15):1414-24.

54. Rosinska J, Lukasik M, Kozubski W. The impact of vascular disease treatment on platelet-derived microvesicles. Cardiovasc Drugs Ther. 2017;31(5-6):627-44.

55. Schrottmaier WC, Kral JB, Badrnya S, Assinger A. Aspirin and P2Y12 inhibitors in platelet-mediated activation of neutrophils and monocytes. Thromb Haemost. 2015;114(3):478-89.

56. Dona M, Fredman G, Schwab JM, Chiang N, Arita M, Goodarzi A, et al. Resolvin E1, an EPA-derived mediator in whole blood, selectively counterregulates leukocytes and platelets. Blood. 2008;112(3):848-55.

57. Lacroix R, Judicone C, Mooberry M, Boucekine M, Key NS, Dignat-George $\mathrm{F}$, et al. Standardization of pre-analytical variables in plasma microparticle determination: results of the international society on thrombosis and haemostasis SSC collaborative workshop. J Thromb Haemost. 2013 April 2. https://doi.org/10.1111/ jth. 12207.

58. Kuravi SJ, Harrison P, Rainger GE, Nash GB. Ability of plateletderived extracellular vesicles to promote neutrophil-endothelial cell interactions. Inflammation. $2019 \mathrm{Feb}$;42(1):290-305.

59. Ettelaie C, Collier ME, Maraveyas A, Ettelaie R. Characterization of physical properties of tissue factor-containing microvesicles and a comparison of ultracentrifuge-based recovery procedures. J Extracell Vesicles. 2014 March 13;4:26901.

Publisher's Note Springer Nature remains neutral with regard to jurisdictional claims in published maps and institutional affiliations. 